\title{
Clinical patterns and their prevalence among adult population with back pain: A community-based cross-sectional study in rural Gadchiroli, India
}

\author{
Shekhar Y Bhojraj ${ }^{1}$, \\ Anand A Bang', \\ Mahesh Deshmukh², \\ Sameer Kalkotwar ${ }^{1}$, \\ Vinay R Joshi ${ }^{3}$, \\ Tushar Yarmal ${ }^{4}$, \\ Raghu Varma ${ }^{1}$, \\ Yogeshwar V Kalkonde², \\ Abhay T Bang ${ }^{2}$ \\ ${ }^{1}$ Spine Foundation, Mumbai, \\ Maharashtra, India \\ ${ }^{2}$ Society for Education, Action \\ and Research in Community \\ Health (SEARCH), Gadchiroli, \\ Maharashtra, India \\ ${ }^{3}$ Hinduja Hospital and Research \\ Center, Mumbai, Maharashtra, \\ India \\ ${ }^{4}$ Naraindas Morbai Budhrani \\ Trust, Mumbai, Maharashtra, \\ India
}

\begin{abstract}
Background: Evaluating clinical patterns and their prevalence of back pain, a common problem in rural areas, can help develop treatment strategies to address this leading cause of disability.

Methods: We conducted a population-based study in rural Gadchiroli, India. In this, two-phase study, trained surveyors conducted a door to door survey (Phase 1) to identify individuals with pain in back and extremities in two villages randomly selected using pre-defined criteria. Those with pain were evaluated by a team of spine surgeons and rheumatologists to diagnose clinical conditions among these patients (Phase 2).

Results: Of the 2535 eligible adults, 2259 (89\%) were screened, 1247 (55\%) reported pain in back and limb and were referred to the specialist clinic. Out of the 906 (73\%) participants who attended the clinics, 783 (89\%) had back/neck pain. The point prevalence of back/neck pain among adults was 49\% (95\% confidence interval (CI)=49\%51\%), non-specific low back pain 45\% (95\% CI=43.4\%-47.5\%); non-specific neck pain $21 \%(95 \% \mathrm{CI}=18.9-22.4)$, radiculopathy $12(95 \% \mathrm{CI}=10.4-13.1)$, myelopathy $0.4(95 \% \mathrm{CI}=0.1-0.7)$ and other serious spinal disorders 0.2 (95\% CI 0.048-0.45). The prevalence of non-specific back/neck pain and radiculopathy was higher among females.

Conclusions Non-specific back and neck pain are the commonest diagnoses among those with pain in the back and extremities, followed by radiculopathy. Serious disorders are rare. Given the high prevalence of non-specific back and neck pain, community health workers and physicians working in rural areas need to be trained systematically to manage these conditions.
\end{abstract}

Musculoskeletal disorders are the commonest cause of disability world over [1-3]. Back pain and other spinal disorders account for a significant number of patients with musculoskeletal disorders. One sixth of the world's population lives in India and more than two-third of population of India lives in rural areas [4]. However, population-level information on the prevalence of the clinical patterns among adults with back pain is limited. A few studies have been conducted in rural India to assess the prevalence of back pain and other musculoskeletal complaints but these have been from the peri-urban and affluent areas $[5,6]$. Conducting such studies is important as a large part of the rural population of India is dependent upon heavy manual labour for earning livelihood. In such a setting, back pain and other spinal disorders are likely to be more prevalent and impose substantial economic and health burden on the individual, the family and the society at large.

This study was undertaken after the people of Gadchiroli district, one of the most underdeveloped districts of India, reported musculoskeletal pain as one of their most important 
health problems. It is a part of a programme to study musculoskeletal disorders in rural Gadchiroli in order to develop appropriate solutions. The objective of this study was to evaluate the clinical patterns among patients with back pain and estimate their prevalence in adults in rural Gadchiroli.

\section{METHODS}

\section{Study setting}

The study was conducted in Gadchiroli district of the Maharashtra state of India. The total population of the district is 1071795 as per the National Census conducted in 2011 [7]. The main source of livelihood is paddy cultivation. Health care is provided primarily through the public health system comprising one large district hospital, 13 smaller rural hospitals, 45 primary health care centers (PHCs) and 376 health subcenters (HSC). In addition, a few non-government organizations, traditional healers, unregistered doctors, private registered practitioners also provide health care.

Society for Education, Action and Research in Community Health (SEARCH) is a non-governmental organization working in this district since 1986 and has a field practice area of 86 villages spread in 3 blocks (revenue divisions of the district). In these villages, community health workers (CHWs) regularly collect population-based information as part of the demographic surveillance system and provide health care for selected ailments. The study was conducted by SEARCH in collaboration with the Spine Foundation, Mumbai a non-profit organisation to promote spine care in India and the rheumatology section, Hinduja Hospital, a large tertiary care hospital in Mumbai, India.

\section{Study design and sample}

This study was a population-based, cross-sectional, interview-based survey of the prevalence of back pain in rural Gadchiroli. The sample size required for the primary study was calculated considering the anticipated point prevalence of non-specific low back pain in the adults ( $\geq 20$ years of age) at $15 \%$. To determine prevalence, with $95 \%$ confidence, precision of 0.02 , design effect of $25 \%$ and non-response rate of $15 \%$ a minimum sample of 1800 adults was needed. Considering the average population of adults in villages in the field practice area of SEARCH at about 1000, 2 villages were needed to be included in the study.

The villages for the study were selected from 86 villages in the field practice area of SEARCH. The inclusion criteria for villages were a) presence of residential male and female $\mathrm{CHW}$ of SEARCH in the village to ensure complete data collection, b) adult ( $\geq 20$ years) population $\geq 1000$, c) villages should be more than $5 \mathrm{~km}$ away from Gadchiroli town and d) the village should not have a hospital or PHC. The aim was to include typical Indian villages of medium size, not too close to an urban area, and where a house to house survey was feasible by the CHWs of SEARCH. Villages with larger adult population ( $>2000)$ were excluded. Seven villages met the eligibility criteria forming the sampling frame of the study. From these seven villages, two villages were randomly selected. The two selected villages, Mudza and Bamhani were 7 and $12 \mathrm{~km}$ from the district headquarter respectively and $20 \mathrm{~km}$ from each other. Both had perennial roads. A health sub center manned by an Auxiliary Nurse and Midwife (ANM) providing immunization and maternity services was present in both the villages. Both the villages were agrarian with farming as the primary source of livelihood. All the resident adults $\geq 20$ years of age of these two villages as recorded in the population register of SEARCH were eligible to be included the study and were recruited through household survey by the CHW.

\section{Data collection}

Adults were screened for pain in the back and extremities (PBE) by trained surveyors using a validated form in a door-to-door survey. Patients with PBE were evaluated in the specialty clinic conducted in the village using a standardized form. This form was pilot tested in a spine and a rheumatology clinic in the city of Mumbai as well as in the rural clinic of SEARCH and modified appropriately before using in the survey. The method of interviewing and clinical examination as well as the clinical and diagnostic definitions and criteria were standardized and the spine surgeons who used these underwent a one-day training workshop.

\section{Data}

The data for the prevalence of pain in back and extremities were collected from 1 January 2010 to 25 January 2010 by the trained CHWs of SEARCH. The CHWs conducted a door to door survey and after taking an informed consent, administered the questionnaire in a face-to-face interview with the eligible male 
and female participants. All patients with PBE were referred to the village-based clinic staffed by a medical team which included spine surgeons, senior rheumatologists, physiotherapist, occupational therapist and a psychologist.

The clinics were organized in respective villages approximately 15 days after the completion of the data collection for the prevalence study to reduce the time period between identification of symptoms (pain in back and extremities) by the CHW and the subsequent examination by the clinician as well as to minimize any possible inconsistencies in the findings of the CHWs and the clinician attributed to the time elapsed between the two visits.

\section{Diagnosis and classification}

The diagnoses were made based on clinical evaluation. Standard operational definitions were used for various clinical diagnoses. Neck pain was defined as midline pain in the region between lower border of occipital bone to the shoulders, upper back pain as midline pain between shoulders to the costal arch and, low back pain was defined as midline pain in the area between the costal arch and the tail bone. Back pain was defined as any pain in neck, upper or lower back. The pain was defined as 'non-specific' if there were no red flags (supplementary panel) which indicated presence of serious underlying disorder. Radiculopathy was diagnosed if individuals had pain along the distribution of the nerve root with or without neurological deficits in the distribution of the nerve root. Myelopathy was diagnosed if the participant had constellation of symptoms and signs suggestive of spinal cord pathology (eg, presence of exaggerated reflexes, Babinski reflex, spasticity, weakness, a sensory level or gait abnormalities). Laboratory and imaging investigations were performed as necessary and were provided free of charge to the patients. Teams also made home visits to the participants who were in the village but were unable to visit the clinic due to disability or age. The patients were managed according to the standard management plan. All the participants were provided with appropriate medicines free of cost for 15 days. The participants were explained the further course of action when there was no relief or if chronic treatment was deemed necessary.

\section{Statistical methods}

The prevalence rates of various clinical conditions were estimated by calculating sex- and age-specific prevalence rates from the respondent population and applying these rates to the non-respondent population to obtain rates for the entire adult population. 95\% confidence intervals (CI) were calculated for these rates. Student's $t$ test was used for comparison of means and Chi square test to compare proportions. Analyses were conducted using Stata 10.0 (Stata Corp, College Station, Texas, USA).

\section{Ethical approval}

The research followed the tenets of the Declaration of Helsinki. Ethical approval for this nested study was granted as part of the main study, by the Institutional Ethical Committee of SEARCH formed according to the guidelines by the Indian Council for Medical Research. Consent was obtained first at the cluster level in the study villages 15 days before starting the survey. The community leaders (Village Council Leaders and members, school teacher and presidents of microfinance self help groups) were explained the purpose and scope of the study including the benefits to the villagers (availability of referral care in SEARCH clinic and the care through a village clinic). Informed written consent in vernacular language in a standard format was obtained from individual participants after explaining the nature and benefits of the study. The benefits provided during the study included free consultation by spine surgeons and rheumatologists in a clinic conducted in the same village at a later date. For those who needed further evaluation, laboratory investigations, as well as imaging with Magnetic Resonance Imaging (MRI) and x-ray including transport were provided free of cost. For patients needing pharmacotherapy, and physiotherapy, these services were also provided free of cost and for those needing surgical interventions, such services were provided at significantly subsidized costs. The CHW discussed these benefits using a printed pamphlet.

\section{RESULTS}

At the time of the study the combined population of both the villages was 3735 . Out of these 2535 were $\geq 20$ years of age and were eligible for the initial screening by the CHWs (phase 1). 2259 (89\%) eligible adults were screened by CHWs and out of these 1247 (55\%) adults PBE. Of these, 906 (73\%) attended the village clinic. Twenty-two participants (2\%) were symptom free on the day of the clinical study and were excluded. The 


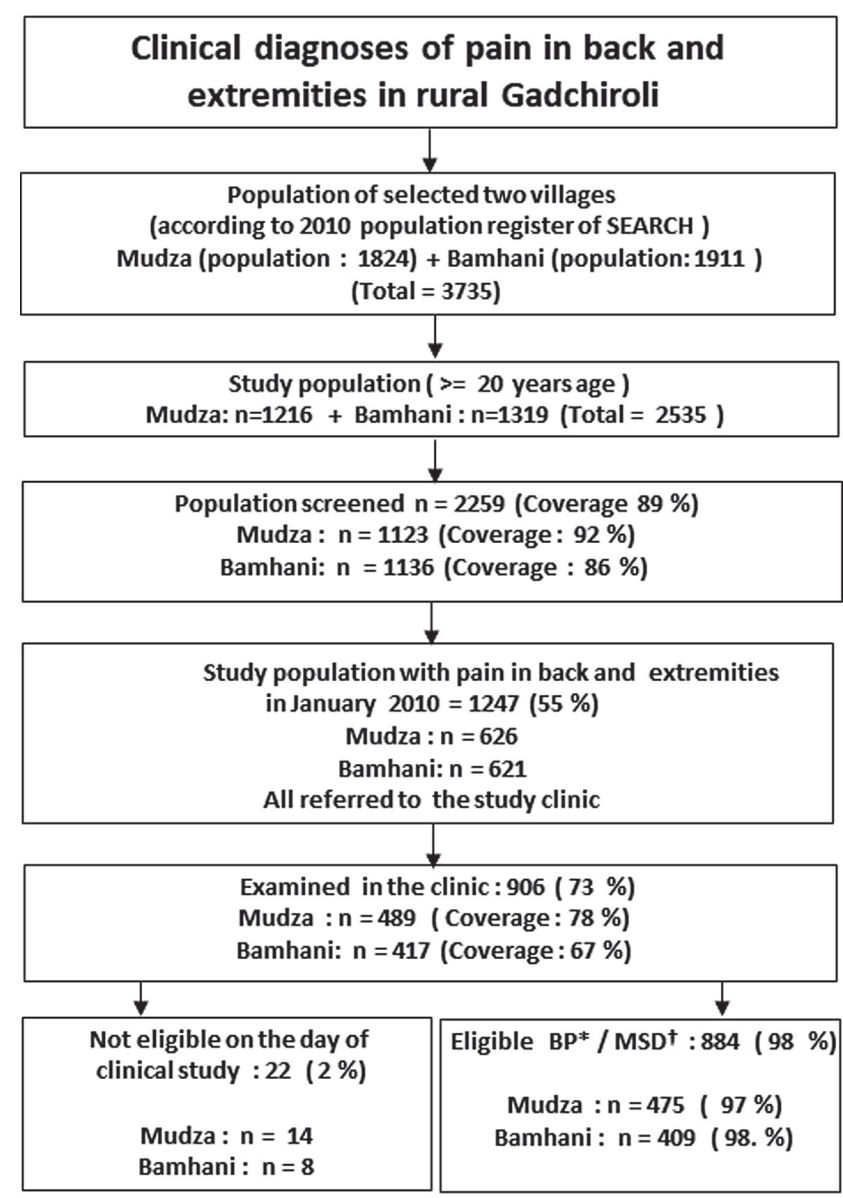

* Back Pain, $\dagger$ Musculoskeletal Disorder

Figure 1. Study design flowchart. study flow is shown in Figure 1. The demographic characteristics of the participants and the non-participants are shown in Table 1. The non-participant group had higher number of younger, literate, labourer and male individuals compared to participants.

The overall point prevalence of back pain in the adult population was 49\%. Non -specific low back pain formed the largest group with a point prevalence of $45 \%$ in the population

Table 1. Demographic characteristics of participants and non-participants in the study

\begin{tabular}{|c|c|c|c|}
\hline CHARACTERISTICS & $\begin{array}{l}\text { PARTICIPANTS } \\
(\mathrm{N}=\mathbf{8 8 4})\end{array}$ & $\begin{array}{c}\text { NON } \\
\text { PARTICIPANTS } \\
(\mathrm{N}=363)\end{array}$ & P-VALUE \\
\hline Mean age (SD) & $48.5(15.3)$ & $43.1(14.4)$ & $<0.001$ \\
\hline \multicolumn{4}{|l|}{ Education, n (\%): } \\
\hline Illiterate & $464(52)$ & $163(45)$ & 0.0148 \\
\hline Females & $558(63)$ & $194(53)$ & 0.0017 \\
\hline Married & $845(96)$ & $340(94)$ & 0.1557 \\
\hline \multicolumn{4}{|l|}{ Caste, $\mathrm{n}(\%)$ : } \\
\hline Scheduled caste & $85(10)$ & $37(10)$ & 0.7552 \\
\hline Scheduled tribe & $129(15)$ & $51(14)$ & 0.8042 \\
\hline Others & $670(76)$ & $275(76)$ & 0.9898 \\
\hline \multicolumn{4}{|l|}{ Occupation, n (\%): } \\
\hline Labour & $351(40)$ & $171(47)$ & 0.016 \\
\hline Farmer & $309(35)$ & $133(37)$ & 0.5722 \\
\hline Service & $22(2)$ & $11(3)$ & 0.5883 \\
\hline Household work & $98(11)$ & $17(5)$ & $<0.001$ \\
\hline Business & $61(7)$ & $23(6)$ & 0.7180 \\
\hline Other & $43(5)$ & $8(2)$ & 0.031 \\
\hline
\end{tabular}

SD - standard deviation

followed by non-specific neck and non-specific upper back pains (prevalence of $21 \%$ and 10\% respectively) (Table 2). The point prevalence of radiculopathy was $12 \%$, myelopathy was $0.4 \%$, spinal tuberculosis was $0.1 \%$, and spinal fracture was $0.1 \%$ (Table 2 ).

The prevalence of non-specific low back pain increased with advancing age (Figure 2). Radiculopathy was common after the fifth decade of life. A higher prevalence among women than men was seen for non-specific low

Table 2. Clinical patterns and their prevalence in the community among adults with back pain

\begin{tabular}{lccc} 
CLINICAL PATTERNS* & $\begin{array}{c}\text { NUMBER } \\
\text { OF } \\
\text { PATIENTS } \\
\text { IN THE } \\
\text { CLINIC }\end{array}$ & $\begin{array}{c}\text { PROPORTION } \\
\text { IN THE } \\
\text { CLINIC } \\
\text { (N = 884) \% }\end{array}$ & $\begin{array}{c}\text { ESTIMATED POINT } \\
\text { PREVALENCE } \\
\text { AMONG ADULTS } \\
\text { \% (95\% CI) }\end{array}$ \\
\hline Nonspecific low back pain & 728 & 82 & $45(43.4,47.5)$ \\
\hline Nonspecific neck pain & 330 & 37 & $21(18.9,22.4)$ \\
\hline Nonspecific mid back pain & 166 & 19 & $10(9.1,11.7)$ \\
\hline Myelopathy & 6 & 1 & $0.4(0.1,0.7)$ \\
\hline Radiculopathy & 187 & 21 & $12(10.4,13.1)$ \\
\hline Serious spinal pathologies: & 3 & 0.3 & $0.2(0.048,0.45)$ \\
\hline Tuberculosis & 1 & 0.1 & $0.1(0.001,0.24)$ \\
\hline Fracture & 2 & 0.2 & $0.1(0.01,0.31)$ \\
\hline
\end{tabular}

CI - confidence interval

* Categories are multiple and not exclusive.

$\uparrow$ Adjusted for non-participants.

$¥$ Suspected in the clinic based on prior radiological investigations available with the patients.
Table 3. Sex-wise estimated point prevalence of clinical patterns among adults with back pain

\begin{tabular}{lccc} 
CLINICAL PATtERnS* & $\begin{array}{c}\text { Ment \% } \\
(95 \% \mathrm{Cl})\end{array}$ & $\begin{array}{c}\text { WOMEnt \% } \\
(95 \% \mathrm{CI})\end{array}$ & P-VALUE \\
$\begin{array}{l}\text { Non-specific low } \\
\text { back pain }\end{array}$ & $34.1(31.3,36.9)$ & $55.7(52.8,58.6)$ & $<0.001$ \\
\hline $\begin{array}{l}\text { Non-specific neck } \\
\text { pain }\end{array}$ & $12.1(10.2,14.2)$ & $28.1(25.5,30.8)$ & $<0.001$ \\
\hline $\begin{array}{l}\text { Non-specific mid } \\
\text { back pain }\end{array}$ & $6.8(5.4,8.5)$ & $13.6(11.7,15.7)$ & $<0.001$ \\
\hline Myelopathy & $0.3(0.05,0.8)$ & $0.4(0.14,1.0)$ & 0.52 \\
\hline Radiculopathy & $7.3(5.8,8.9)$ & $14.6(12.6,16.8)$ & $<0.001$ \\
\hline $\begin{array}{l}\text { Serious spinal } \\
\text { pathologies }\end{array}$ & $0.3(0.09,0.92)$ & $0.1(0.002,0.48)$ & 0.16 \\
\hline Tuberculosis & $0.0(0,0.33)$ & $0.1(0.002,0.48)$ & 0.32 \\
\hline Fracture & $0.3(0.09,0.92)$ & $0.0(0,0.32)$ & 0.04 \\
\hline
\end{tabular}

$\mathrm{CI}$ - confidence interval

*Categories are multiple and not exclusive.

$\uparrow$ Adjusted for non-participants. 


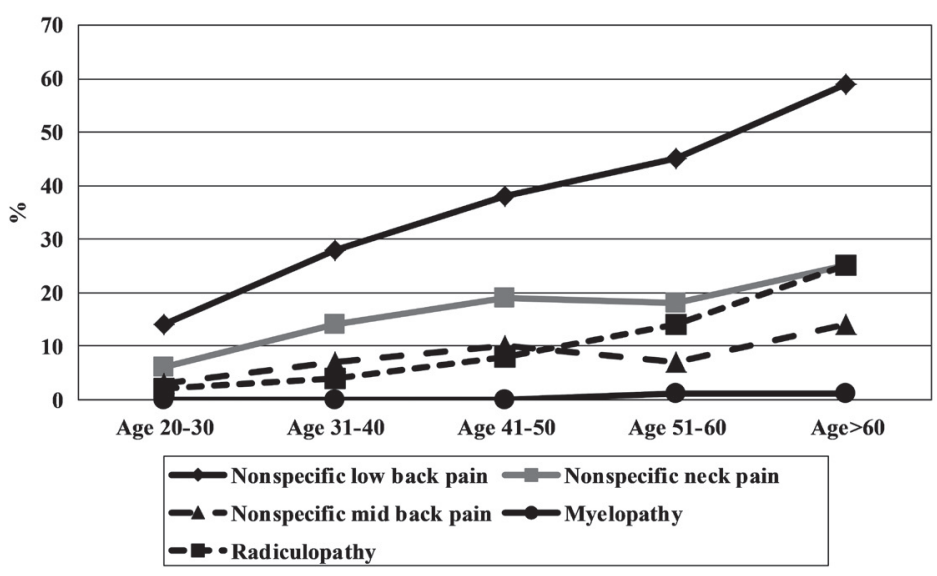

Figure 2. Age-wise population prevalence of clinical patterns of back pain. back pain ( $55.7 \%$ vs $34.1 \%, P<0.001)$, non-specific neck pain $(28.1 \%$ vs $12.1 \%, P<0.001)$ and non-specific mid-back pain $(13.6 \%$ vs $6.8 \%, P<0.001)$ and radiculopathy (14.6\% vs $7.3 \%, P<0.001$ ) (Table 3 ).

\section{DISCUSSION}

Among those with back pain, half of the adults had non-specific back pain, about quarter had non-specific neck pain and one in eight individuals had radiculopathy. Serious disorders such as myelopathy, tuberculosis of spine and spinal fractures were rare. The prevalence of non-specific back and neck pain was almost two times higher among women compared to men. The prevalence of non-specific back pain increased with age.

The prevalence of back pain in our study is higher than that reported from rural India or rural regions of Asia and South America [8]. The higher prevalence in the present study could be due to the predominant agrarian nature of the population where most of the individuals were farmers and involved in heavy physical labour. A study done in China had shown higher risk of low back pain among those involved in activities with heavy physical stress compared to those with mild physical stress [9]. In addition, lack of access to formal health care in this area could be a factor responsible for higher prevalence of back pain.

Among those with non-specific back pain the highest prevalence was seen for low back (45\%) followed by neck $(21 \%)$ and mid-back pain (10\%). The pattern of pain being most common in the lower back followed by neck and mid-back was similar to those reported from other studies in rural India as well as other parts of the world [10].

The prevalence of non-specific back pain as a whole and at individual sites was almost two times higher among women compared to men. These findings are in agreement with previously published studies which have shown the prevalence of back pain to be higher among women [11,12].

Very little is known about the prevalence of spinal and neurological disorders other than non-specific back pain among those with PBE. In our study the prevalence of radiculopathy among adults was 12\% (95\% CI=10.4\%$13.1 \%)$. The prevalence of myelopathy, spinal tuberculosis and spinal fractures was low at $0.4 \%, 01 \%$ and

Box 1. Red flags in patients with low back pain.

History:
1. Bladder/ bowel incontinence.
2. Peri-anal anesthesia.
3. Pain at night/ rest pain or constant pain.
4. Claudication in the lower limbs.
5. Thoracic pain.
6. Weight loss (subjectively perceived by the patient).
7. Fever (of at least 15 days in the recent past).
8. Past history of tuberculosis or cancer.
9. Difficulty in walking due to trauma- unstable gait,
imbalance, tendency to fall, or requires support.
10. Deformity - coronal or sagittal, frontal or sideways.
11. Things falling from hand.
12. Tingling and / or numbness in hands.
Examination:
1. Toe or heel walking not possible due to weakness.
2. Weak hand grip and pinch.
3. Difficulty in bending (anyways).
4. Positive straight leg raising (SLR) test with pain on
raising legs at less than $30^{\circ}$.

$0.1 \%$ respectively.

Given the high prevalence of back pain and other spinal disorders which are associated with significant disability [3] and health care costs [13], a health care workforce needs to be created to treat disorders in rural areas. Since the prevalence of back pain was high and most of the back pain in the population was non-specific, village-level Accredited Social Health Activists (ASHAs) in the public health system in India or other community health workers can potentially provide care for this problem. These workers can be trained to refer those with red flags (Box 1) and treat patients with non-specific pain at the village level. Use of community health workers could be an important strategy to reduce the burden of back pain in the community. Patients with radiculopathy can be managed by the physicians at the primary health centers while those with myelopathy and other serious spinal disorders will need to be seen by internists or orthopedic surgeons at the district level. Patients needing spine surgeries need services of the spine surgeons or neurosurgeons who typically practice in large city centres.

The study has several strengths such as being a community-based study from rural area of one of the underdeveloped districts of India with coverage close to $90 \%$ in the screening survey and the use of standardized questionnaires. The clinical evaluation was done by a team of clinical experts. There are also some limitations. The diagnosis 
was largely based on clinical examination. To mitigate this limitation, we used standardized case definitions and the team of clinicians was trained in a workshop so that same diagnostic criteria are used. Conducting community-based studies in resource limited settings remains challenging and use of standard clinical definitions is a common and accepted practice in large community-based prevalence studies. Furthermore, among those referred to the clinic, only about $70 \%$ actually attended the clinic which could result in a bias in the estimation of the point prevalence. To mitigate this limitation to some extent, we calculated sex- and age-specific prevalence among respondents and applied these rates to the non-respondent population to obtain prevalence in the entire adult population. Also, those without symptoms of back pain at the time of the initial screening survey could have been missed. This is likely to result in underestimation of the prevalence of back pain.

\section{CONCLUSION}

Our study, conducted in one of the poorest communities of India, shows that among those with pain in the back and the extremities, almost one in two individuals had non-specific back or neck pain. Radiculopathy is present in one in eight individuals. Serious spinal disorders are rare. Female sex and advancing age were associated with increasing prevalence of these disorders. The health care providers working in rural areas of India need to be trained to manage these disorders, given the high prevalence of back pain and provisions need to be made to provide care for this problem through the public health care system.

\footnotetext{
Acknowledgements: We thank the people, community health workers, volunteers and leaders of the village Mudza and
Bamhani who participated in the study and made all the arrangements. We thank Dr Rani Bang, SEARCH, Gadchiroli for
her support in conceiving and conducting the study. We thank Dr Shital Mohite, Dr Smruti Ramteke and Dr Balkrishna
for participating in data collection.
Funding: The study was funded by Sir Dorabji Tata Trust, the Spine Foundation, Mumbai, and SEARCH, Gadchiroli, India.
Authorship contributions: Conceived and designed the study: AAB, ATB, SYB, VRJ, MD, SK, RV. Conducted the study:
SYB, VRJ, SK, RV, AAB, MD, TY, ATB. Analysed the data: MD, AAB, ATB. Contributed materials / analysis tools: SYB, SK,
VRJ, RV. Wrote the draft manuscript: YK. Reviewed the manuscript: ATB.
Competing interests: The authors completed the ICJME Declaration of Interest Form (available upon request from the
corresponding author) and declare no conflicts of interest.
}

1 Woolf AD, Pfleger B. Burden of major musculoskeletal conditions. Bull World Health Organ. 2003;81:646-56. Medline: 14710506

2 Woolf AD. The bone and joint decade 2000-2010. Ann Rheum Dis. 2000;59:81-2. Medline:10666159 doi:10.1136/ard.59.2.81

3 Vos T, Flaxman AD, Naghavi M, Lozano R, Michaud C, Ezzati M, et al. Years lived with disability (YLDs) for 1160 sequelae of 289 diseases and injuries 1990-2010: a systematic analysis for the Global Burden of Disease Study 2010. Lancet. 2012;380:216396. Medline:23245607 doi:10.1016/S0140-6736(12)61729-2

4 Census of India: Area And Population. Available: http://censusindia.gov.in/Census_And_You/area_and_population.aspx. Accessed: 25 July 2019.

5 Chopra A, Patil J, Billempelly V, Relwani J, Tandle HS. Prevalence of rheumatic diseases in a rural population in western India: a WHO-ILAR COPCORD Study. J Assoc Physicians India. 2001;49:240-6. Medline:11225138

6 Mathew AJ, Chopra A, Thekkemuriyil DV, George E, Goyal V, Nair JB, et al. Impact of musculoskeletal pain on physical function and health-related quality of life in a rural community in south India: a WHO-ILAR-COPCORD-BJD India study. Clin Rheumatol. 2011;30:1491-7. Medline:21853278 doi:10.1007/s10067-011-1824-0

7 Collectorate Gadchiroli. Available: http://gadchiroli.nic.in/. Accessed: 25 July 2019.

8 Chopra A. The COPCORD world of musculoskeletal pain and arthritis. Rheumatology (Oxford). 2013;52:1925-8. Medline:23843110 doi:10.1093/rheumatology/ket222

9 Barrero LH, Hsu Y-H, Terwedow H, Perry MJ, Dennerlein JT, Brain JD, et al. Prevalence and physical determinants of low back pain in a rural Chinese population. Spine. 2006;31:2728-34. Medline:17077743 doi:10.1097/01.brs.0000244583.35982.ea

10 Chopra A, Abdel-Nasser A. Epidemiology of rheumatic musculoskeletal disorders in the developing world. Best Pract Res Clin Rheumatol. 2008;22:583-604. Medline:18783739 doi:10.1016/j.berh.2008.07.001

11 Schneider S, Randoll D, Buchner M. Why do women have back pain more than men? A representative prevalence study in the federal republic of Germany. Clin J Pain. 2006;22:738-47. Medline:16988571 doi:10.1097/01.ajp.0000210920.03289.93

12 Hoy D, Bain C, Williams G, March L, Brooks P, Blyth F, et al. A systematic review of the global prevalence of low back pain. Arthritis Rheum. 2012;64:2028-37. Medline:22231424 doi:10.1002/art.34347

13 van Tulder M, Koes B, Bombardier C. Low back pain. Best Pract Res Clin Rheumatol. 2002;16:761-75. Medline:12473272 doi:10.1053/berh.2002.0267 